\title{
In vitro and in vivo Exploration of Super-magnetically Modulated Novel Parenteral Carrier: A Targeted Drug Delivery of Polymeric Carboplatin Nanosphere Capped with the Vitamin C to Treat Breast Cancer in Rats
}

\author{
Ullas Prakash D'Souza', Nitish Rao², Ravi Gundadka Shriram², Akhilesh Dubey2,* \\ ${ }^{1}$ Department of Pharmacology, NGSM Institute of Pharmaceutical Sciences, NITTE (Deemed to be University), Mangaluru, Karnataka, \\ INDIA. \\ 2Department of Pharmaceutics, NGSM Institute of Pharmaceutical Sciences, NITTE (Deemed to be University), Mangaluru, Karnataka, \\ INDIA.
}

\begin{abstract}
Introduction: Super-magnetically modulated nanosphere of carboplatin (CPt) capped with vitamin $\mathrm{C}$ and uncapped Nano sphere of CPt were developed and evaluated for their use as a targeted drug delivery system. Objectives: The objective of the study was to encounter multiple problems such as to circumvent the snag caused by the larger molecules, increase the target ability of magnetic particle and synergize the impact of carboplatin with antioxidant effect. Methods: Particulate carriers for magnetic drug delivery were prepared by an emulsion-solvent evaporation method. The in vitro parameters such as drug entrapment efficiency, particle size analysis, Scanning Electron Microscopy (SEM), Differential Scanning Calorimetry (DSC), percentage magnetite content, swelling kinetics, in vitro magnetic responsiveness, in vitro drug release and kinetics study, in vitro antioxidant study were conducted followed by an in vivo anticancer study in rats to confirm the product efficacy or therapeutic benefits. Results: The maximum drug entrapment efficiency was found to be $88.93 \% \pm 0.77$ at the higher concentration of polymers and considered to be good. SEM ensured spherical shape and coating of vitamin C, mean particle size and PDI value of F3 was found to be $150 \mathrm{~nm}$ and 0.251 respectively, DSC proved no significant interaction, maximum magnetite content was found in F3. Vitamin C coated carboplatin Nano sphere showed excellent in vitro antioxidant free radical-scavenging activity. Biphasic behaviour was not observed in the formulations F1-F3 however, F4-F6, displayed initial burst release followed by sustained release over a period of $24 \mathrm{~h}$. The kinetic study suggested diffusion coupled with erosion release pattern. in vivo results showed that F-3 in the presence of the magnetic field had effectively suppressed breast cancer cells. Conclusion: The current study opens up new vistas in cancer treatment and established better in vitro-in vivo co-relationship under the diseased state.
\end{abstract}

Key words: Carboplatin, Ethyl cellulose, Magnetite, Vitamin C, Nanopshere.

\section{INTRODUCTION}

The prevelance of cancer has increased worldwide, as indicated by the global cancer statistics. ${ }^{1}$ Statistics also indicated that despite several novel and innovative strategies, the detection and treatment of cancer is extremely difficult. Among Indian women, breast cancer is the most common type of cancer prevalent in India. Breast cancer is now the most common cancer in most cities in India and $2^{\text {nd }}$ most common in rural areas. ${ }^{2}$ Despite the prodigious effort made by researchers worldwide, this
Submission Date: 07-11-2019; Revision Date: 26-12-2019; Accepted Date: 26-02-2020.

DOI: 10.5530/ijper.54.2s.70 Correspondence: Dr. Akhilesh Dubey Assistant Professor, Department of Pharmaceutics, NGSM Institute of Pharmaceutical Sciences, NITTE (Deemed to be University), Deralakatte, Mangaluru-575018, Karnataka, INDIA.

Phone: +91-9986893787

E-mail: akhilesh@nitte.edu.in

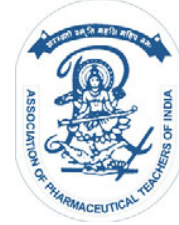

www.ijper.org 
complex and diverse disease is one of the most dreadful conditions in the developed world as well. This scenario is expected to intensify in the future too and therefore effective and targeted treatment is required to tackle the intensity of breast cancer. Breast cancer is made of fat, glands and connective (fibrous) tissue and it has several lobes, divided into lobules that end in the milk glands. Tiny ducts run from the many tiny glands and at the end of nipple, they connect together. $80 \%$ of breast cancers occur in these tiny lobes and the condition is known as ductal cancer. Lobular cancer develops in the lobules and is accountable for $10-15 \%$ of breast cancers. Although, primarily breast cancer is a disease of women which is the leading cause of deaths in women, however, $1 \%$ of breast cancers occur in men too. The majority of breast cancers are triple-negative breast cancers because they do not overexpress oestrogen receptors, progesterone receptors, or human epidermal growth factor receptors 2.2 and 2.3. ${ }^{3}$ The effective option to treat such cancers is chemotherapy; however, because of large dose requirements and random distribution of the drugs in the body, chemotherapy is always associated with several sets of side effects. ${ }^{4}$

Nanosphere (NS) with super magnetic power is gaining popularity in the treatment of cancer therapy. ${ }^{5-7}$ They are made up of a solid core that is surrounded by thick polymer and the size ranges from $100-500 \mathrm{~nm} .{ }^{8}$ Nanosphere manifests several advantages such as uncomplicated surface modification, high circulation time in the plasma, enhances drug loading and highly stable in the reticuloendothelial system. Magnetic Nanosphere (MNS) as drug carriers provide a huge opportunity in the treatment of cancer as targeted carriers and thereby reduce the side effects associated with conventional chemotherapy. ${ }^{7}$ Magnetic drug delivery, a particulate carrier system, is a very efficient method of delivering the drugs to the localized disease site. This method of drug delivery can deliver very high concentrations of chemotherapeutic or radiological agents near the target site, such as a tumour, with a minimum scope of toxic effects to normal surrounding tissue or the whole body. Magnetic Nanosphere (MNS) are capable of accumulating in desired locations within the body under the influence of the applied magnetic field. ${ }^{10,11}$ Magnetic Nanosphere (MNS), i.e., incorporation of magnetic particles into drug carrier (polymers) system and application of an external magnetic field is a unique way of targeting the drugs directly to the desired site. MNS is tiny particles (100-200 nm), so they can circulate through the blood capillaries without producing embolic occlusion however, they are susceptible (ferromagnetic) to be captured in minor vessels and dragged into the adjacent tissue by magnetic fields of 0.5-0.8 Tesla (T). Size, shape and surface charge of MNS can determine the endocytosis, trans-cellular transport, passive targeting and retention effect and thus determine the performance of the delivery system. Bulte JWM et al. Report application of a magnetic field to be nontoxic to biological systems and adaptable to any part of the body. ${ }^{12}$ It was also reported that up to $60 \%$ of an injected dose could be stored and released in a controlled manner in selected non-reticuloendothelial organs. ${ }^{12}$ The novelty involved herein, MNS can target tumours with fewer side effects and toxicity and can bypass p-glycoprotein leading to better efficacy. ${ }^{13,14}$

Carboplatin $(\mathrm{CPt})$ is an alkylating agent preventing DNA synthesis and RNA transcription in cancer affected cells. They have reported it that administration of CPt by IV route can cause serious or life-threatening side effects like haematologic, gastrointestinal, hepatic, neurologic toxicities and acute nephrotoxicity which limit the amount of drug to be given to the patient. ${ }^{15}$ Nevertheless, it is possible to deliver a relatively high dose of antineoplastic drugs to tumour-bearing regions, while minimizing the systemic exposure to the drugs. ${ }^{16}$ Hence, to overcome the stumbling block in the parenteral drug delivery of $\mathrm{CPt}$, the current study was an attempt to provide a new lease of life to parenteral delivery of CPt by using magnetically responsive nanosphere which enhanced the therapeutic efficacy of the drug at lower doses and thereby reduced the toxic effects. It has been reported in a few scientific literatures that the use of vitamin $\mathrm{C}$ in combination with chemotherapy drugs increases the antitumor activity and also enhances the bioavailability of the magnetic carrier. ${ }^{17}$ The circulation time of nanoparticles in blood increases with the decreasing particle size and generally, large particles are swiftly engulfed by the macrophages and also speedily absorbed by the reticuloendothelial system which is later accumulated in the liver and fend off the bioavailability in the blood. ${ }^{18}$ Therefore, the capping of MNS was done by using Vitamin $\mathrm{C}$ to increase the circulation time of MNS in the blood with the synergistic effect in the therapy. Vitamin $\mathrm{C}$ is water soluble and renowned for its antioxidant property and can also target redox imbalance, epigenetic reprogramming and oxygen sensing regulation. ${ }^{18-20}$

Therefore, the magnetic nanosphere with vitamin C (MNSVC) was developed to encounter multiple problems such as to circumvent the snag caused by the larger molecules, increase the target ability of magnetic particle and synergize the impact of carboplatin with antioxidant effect. 


\section{MATERIALS AND METHODS}

\section{Materials}

Carboplatin and DMBA (7, 12 dimethylbenz (a) anthracene) were procured from Sigma-Aldrich Corporation, (St Louis, USA). Ethyl cellulose, sodium phosphate, sodium chloride, Di sodium hydrogen phosphate, ferric chloride and sodium thiosulphate were procured from CDH (P) Ltd, (New Delhi, India). Magnesium stearate was obtained from Thomas Baker, (Mumbai, India). Vitamin C (L-Ascorbic acid 99\%) was purchased from Loba chemie Pvt, Ltd.Mumbai, India. Potassium dihydrogen phosphate was procured from Hi-Media Laboratories Pvt Ltd, (Mumbai, India). Sodium hydroxide, Tween 80 and Liquid paraffin were purchased from Merck India Limited, (Mumbai, India). All other chemicals/reagents used were of analytical grade.

\section{Animals}

Antitumor efficacy study was carried out using 4-7 week-old female Sprague-Dawley rats weighing 150200 g. Group of rats were housed in polypropylene cages. Paddy husk was provided as bedding material for rats, which was changed every day and provided with standard food pellets (diet composition, wheat brokenmoisture $9.0 \%$, crude protein $11.5 \%$, crude fat $1.9 \%$, crude fibre $4.0 \%$, ash $0.2 \%$ and nitrogen-free extract $73.4 \%$ ) and tap water. The animals were maintained at a controlled temperature $\left(28 \pm 1^{\circ} \mathrm{C}\right)$ and the light conditions (12-12 hr, day and night cycle). Cleaning and sanitation work was done on alternate days. The animals were allowed to acclimate for 1 week before the experiment. The animals were maintained as per CPCSEA regulations and the experimental protocol was approved by the institutional animal ethics committee (KSHEMA/AEC/23/2010) KSHEMA，Deralakatte, Mangalore (Karnataka).

\section{Methods}

\section{Compatibility studies}

Compatibility of the drug CPt with excipients such as ethyl cellulose, magnetite $\left(\mathrm{Fe}_{3} \mathrm{O}_{4}\right)$ and Ascorbic acid used to formulate MNS and MNSVC was established by Infrared (IR) spectral analysis using FTIR spectrometer (Alpha Bruker, Japan). IR spectral analysis was carried out to evaluate any chemical interaction of the drug with the excipients after combining them.

\section{Preparation of Carboplatin nanosphere (CPtNS) and Carboplatin magnetic nanosphere coated with Vitamin C (CPtMNSVC)}

\section{CPtNS and CPtMNSVC were prepared in two steps}

The first step involves the preparation of magnetite by the oxidation of ferrous hydroxide. The second step is the preparation of MNS using biodegradable polymer and magnetite prepared in the first step along with the drug. Ethyl cellulose (polymer) encapsulates the drug in matrix and facilitates controlled release, while magnetite imparts magnetic properties to the formulated MNS.

\section{Preparation of magnetite}

Magnetite was synthesised by dissolving $13.9 \mathrm{~g}$ of ferrous sulphate in $70 \mathrm{~mL}$ of water and this solution was aerated. Sodium hydroxide (4.1 g) solution in $30 \mathrm{~mL}$ of water was added to the above solution. This mixture was heated at $50^{\circ} \mathrm{C}$, in a temperature-controlled water bath and maintained for five hours along with aeration to give cubic magnetite powder and also $\mathrm{pH}$ maintained at 4.5. At the bottom of the beaker, the magnet was placed to allow the magnetite particles to sediment. The supernatant fluid was removed. The settled particles were washed with $3 \times 100 \mathrm{~mL}$ of distilled water and dried at room temperature. Later, digested MNS (1 mL) solution allowed reacting with $1 \mathrm{~mL}(5 \% \mathrm{w} / \mathrm{v})$ solution of potassium ferrocyanide to get an intense blue precipitate, which was insoluble in dilute hydrochloric acid and decomposed on the addition of sodium hydroxide solution. $^{21-24}$

\section{Preparation of CPtNS AND CPtMNS}

Emulsion-solvent evaporation technique was followed to prepare the nanosphere by using the polymer (ethyl cellulose). Ethyl cellulose was dissolved in $10 \mathrm{~mL}$ of acetone followed by addition of drug in the polymer solution and shaken vigorously to form uniform drugpolymer dispersion. To the above solution, magnetite was added and dispersed, which imparts magnetic properties to the prepared nanosphere. This organic solution was poured into light liquid paraffin $(50 \mathrm{~mL})$ containing one drop of span 80, stirred for $30 \mathrm{~min}$ at $1000 \mathrm{rpm}$ and then the dispersion was sonicated. Sonication was done in 2 cycles. During the first cycle, the dispersion was sonicated at $80 \%$ amplitude with a pulse of 0.5 cycles per s for a period for $1 \mathrm{~min}$, followed by $1 \mathrm{~min}$ rest. After $1 \mathrm{~min}$, the second cycle was processed for $1 \mathrm{~min}$ at $80 \%$ amplitude with $0.5 \mathrm{~s}$ pulse for another $1 \mathrm{~min}$. and then the system was continuously stirred for four hours to allow complete evaporation of the solvent. The MNS was filtered, washed with n-hexane and dried at room temperature. $^{25-28}$

\section{Preparation of CPt MNSVC}

By adjusting the $\mathrm{pH}$ and temperature, the prepared magnetite nanospheres were capped with ascorbic acid and the $\mathrm{pH}$ of the dispersion was maintained at 12.5 by adding $10 \mathrm{~N}$ ammonia. vitamin $\mathrm{C}(10 \mathrm{mg})$ was added into the magnetite dispersion and stirred for $1 \mathrm{~h}$ at $60^{\circ} \mathrm{C}$ to secure stable vitamin $C$ coated magnetic nanospheres. ${ }^{28}$ The MNSVC was subjected to dialysis against water for 
three days to remove access to ascorbic acid and base. ${ }^{29}$ Total six batches of ethyl cellulose nanospheres with vitamin $\mathrm{C}$ in the presence of magnetite and the absence of magnetite and vitamin $C$ were prepared. (Table 1)

To examine the solvent evaporation rate, all the dispersed and continuous phase removed into a vessel and weighed and then dried at $105^{\circ} \mathrm{C}$ for $6 \mathrm{~h}$ in an oven and reweighed again. The amount of residual solvent was calculated from the weight loss after drying. The percentage of solvent evaporation was determined from the following equation ${ }^{30}$

Percentage evaporated $=\frac{\text { Initial amount }- \text { residual amount }}{\text { initial amount }} \times 100$

\section{Characterization of CPtMNSVC and CPtMNS} Determination of drug entrapment efficiency (\%)

CPtMNS was analysed by quantifying both the unentrapped and entrapped drug. CPtMNS (15 mg) was weighed, mixed with water and stirred for a certain period $(30 \mathrm{~s})$. The suspension was filtered through 0.45 $\mu$ filter and the supernatant was analysed using a UVVisible spectrophotometer (UV-1700 Shimadzu Corporation, Tokyo, Japan) at $224 \mathrm{~nm}$ for free drug content. The residue obtained was extracted in $50 \mathrm{~mL}$ of solvent mixture $(2.5 \mathrm{~mL} 0.1 \mathrm{~N} \mathrm{HCl}$ and $47.5 \mathrm{~mL} \mathrm{PBS} \mathrm{pH} \mathrm{7.4)} \mathrm{by}$ stirring for $15 \mathrm{~min}$ at $1500 \mathrm{rpm}$. The digested homogenate was centrifuged and the supernatant was analysed spectrophotometrically at $224 \mathrm{~nm}$ to calculate the drug concentration from the standard curve. The impact of the coating of vitamin $\mathrm{C}$ in the nanosphere were also accessed. ${ }^{31-34}$

$\%$ Drug entrapment Efficiency $=\frac{\text { Experimental drug content }}{\text { Theoretical drug content }} \times 100$

\section{Particle size analysis}

The average particle size (in $\mathrm{nm}$ ) and size distribution, poly dispersibility index (PDI) of the CPtMNSVC and $\mathrm{CPtNS}$ were measured using a Malvern nano zeta sizer instrument (Malvern Zeta Sizer Nano ZS, Malvern Instruments Ltd., Malvern, UK).

\section{Scanning electron microscopy (SEM)}

SEM is a widely used technique for the structure characterisation of nanoparticles and was employed to characterise the surface topography of nanosphere. CPtMNSVC was compared with CPtNS because surface and texture changes occured after the coating of nanosphere, which was performed using JEOL, JSM5610LV Scanning microscope (Japan). ${ }^{35}$

\section{Determination of percent magnetite content}

The determination of $\mathrm{Fe}_{3} \mathrm{O}_{4}$ content in CPtNS was measured by employing a conventional method using thiosulphate and potassium iodide for quantitative analysis. This was done by destroying the MNS by gently heating while mixing them with the help of a magnetic stirrer for a few min, which resulted in the formation of a yellow homogeneous solution. An accurately weighed amount of MNS (after destruction by gentle heating) was dissolved in the mixture of water $(200 \mathrm{~mL})$ and Conc. $\mathrm{HCl}$ by heating it to the boiling point. The solution was then boiled for $15 \mathrm{~s}$ and cooled rapidly. Then potassium iodide $(3 \mathrm{~g})$ was added and kept in the dark for $15 \mathrm{~min}$, the liberated iodine was then titrated with $0.1 \mathrm{~N}$ sodium thiosulphate $\left(\mathrm{Na}_{2} \mathrm{~S}_{2} \mathrm{O}_{6}\right)$ using starch as an indicator. A blank titration was carried out. The difference between titrations gave the amount of iodine liberated by ferric ion. Each $\mathrm{ml}$ of $0.1 \mathrm{~N}$ sodium thiosulphate $\approx 0.005585 \mathrm{~g}$ of ferric ion. ${ }^{36,37}$

\section{Swelling kinetic}

Swelling kinetics of the CPtMNSVC was determined by the swelling ratio (SR) at a given time. Dried MNS were immersed in distilled water and were frequently weighed after removing the excess water on the surface using filter paper. The SR, (Ws + Wd) / Wd, is defined as the ratio of the total weight of water in swollen MNS to the weight of the dried MNS, where, Ws is the weight of absorbed water (wet weight of the MNS was recorded during the swelling period at regular time intervals) and Wd is the weight of the MNS at dry state. ${ }^{38}$

\section{Differential scanning calorimeter (DSC)}

The thermal behaviour of carboplatin, magnetite and ethyl cellulose nanosphere was analysed using a DSC instrument (Shimadzu, Kyoto, Japan). The samples were heated at a rate of $5^{\circ} \mathrm{C} / \mathrm{min}$ from 25 to $300^{\circ} \mathrm{C}$ and purged with the atmosphere of nitrogen at a flow rate of $30 \mathrm{~mL} / \mathrm{min}$. Indium (m.p. $=156.8^{\circ} \mathrm{C}$ ) was used as the standard reference materials to calibrate the temperature and energy scales of the DSC instrument. ${ }^{39,40}$

\section{In vitro magnetic responsiveness}

This special apparatus was fabricated to conduct an in vitro magnetic responsiveness study, consisting of a Millipore pump, as shown in Figure 1. The experiment was conducted at room temperature $\left(21-25^{\circ} \mathrm{C}\right)$. Air was pumped into the flask, thereby a flow of normal saline through the glass tube was improved and consequently, it was exposed to an electromagnet. The flow within the glass tube was controlled at a rate of $3 \mathrm{~mL} / \mathrm{min}$ $(0.5 \mathrm{~cm} / \mathrm{s})$ by regulating the pump pressure. CPtNS $(15$ $\mathrm{mg} / \mathrm{mL}$ ) were dispersed in normal saline containing $0.1 \% \mathrm{w} / \mathrm{v}$ tween 80 and run through the capillaries. To resemble the blood flow rate which passed through the capillaries, a flow of $0.5 \mathrm{~cm} / \mathrm{s}$ of normal saline were 
maintained and a $1 \mathrm{~mL}$ aliquot of the CPtMNS was injected into the injection site. The $0.21 \mathrm{~K}$ gauss magnetic field was established at a distance of $3 \mathrm{~cm}$ from the tube for $15 \mathrm{~min}$ and a sample was collected every min. Further, the magnetic field was removed and samples were collected for $5 \mathrm{~min}$. In the collected samples, CPtNS content was evaluated using a UV-Visible spectrophotometer at $224 \mathrm{~nm}^{39,40}$

\section{In vitro drug release study}

The in vitro release study of CPtMNSVC and CPtNS was carried out using the dialysis tube method. CPtMNSVC and CPtNS $(15 \mathrm{mg} / \mathrm{mL})$ were placed in the dialysis bag, which was immersed in $20 \mathrm{~mL} 0.2 \mathrm{M}$ PBS containing $0.1 \%(\mathrm{v} / \mathrm{v})$ tween 80 . The $\mathrm{pH}$ and temperature of the dissolution medium were maintained at 7.4 and $37^{\circ} \mathrm{C}$ respectively, with $100 \mathrm{rpm}$ shaking. Test samples were withdrawn from the medium at predetermined time intervals for a period of $12 \mathrm{hr}$. At each time point, an equal volume of the dissolution medium was added into the beaker to maintain the sink condition. ${ }^{41}$ Triplicate experiments were conducted for each study and analyse to quantify carboplatin and ascorbic acid content spectrophotometrically at a wavelength of $224 \mathrm{~nm}$ and 271 $\mathrm{nm}$ respectively. The in vitro drug release data that was obtained from CPtMNSVC and CPtNS were kinetically treated using various mathematical models like zero order, first order, Higuchi model and Korsmeyer-Peppas model to determine the order of drug release. ${ }^{42-44}$

\section{In vitro antioxidant study}

The free radical scavenging activity of CPtMNSVC was measured using the 2, 2-diphenyl-1-picrylhydrazyl (DPPH) method. An amount of a $0.2 \mathrm{mM}$ solution of $\mathrm{DPPH}$ in methanol was prepared and $100 \mu \mathrm{L}$ of this solution was added to CPtMNSVC $(15 \% \mathrm{w} / \mathrm{w}$ of ascorbyl-6-palmitate) at concentrations of 10, 20, 30, 40 and $50 \mu \mathrm{g} / \mathrm{mL}$. After $30 \mathrm{~min}$, absorbance was measured at $517 \mathrm{~nm}$ using an ELISA plate reader (AM-2100, Alere Inc., USA) vitamin $C$ was used as the reference standard. The following equation was used to calculate the percentage of anti-oxidant activity. ${ }^{45,46}$

$\%$ Inhibition of DPPH $=\frac{\text { Absorption }(\text { control })-\text { Absorption }(\text { sample })}{\text { Absorption }(\text { control })} \times 100$

\section{In vivo anticancer studies}

The main objective of the in vivo targeting study was to assess the impact of the presence and absence of a magnetite. Therefore the study was carried to compare the targeting efficiency of drug loaded magnetic nanosphere with vitamin $\mathrm{C}$ and drug-loaded nanosphere without vitamin C. The selection of doses of drug was done based on the human prescribing doses and these human doses were selected and converted into animal dose. ${ }^{47,48}$ The dose of $\mathrm{CPt}$ to be administered in rats was calculated according to the body surface ratio of the rat to human beings.

Rats were divided into four groups consisting of six animals in each group as a standard, breast cancer control (BCC), test 1 and test 2 . They were maintained at a temperature of $28 \pm 1^{\circ} \mathrm{C}$ with the relative humidity of $60 \%$ (12 hr light and $12 \mathrm{hr}$ dark cycle) and provided with standard food pellets (diet composition, wheat brokenmoisture $9.0 \%$, crude protein $11.5 \%$, crude fat $1.9 \%$, crude fiber $4.0 \%$, ash $0.2 \%$, nitrogen-free extract $73.4 \%$ ) and tap water. Rats were administered with a single s.c injection of DMBA (7, 12-dimethylbenz (a) anthracene) in $1 \mathrm{~mL}$ sesame oil at a dose of $25 \mathrm{mg}$ to the breast by air pouch technique. After 28 days of induction, animals were palpated weekly and the following parameters were evaluated. (Table 2)

Tumour yield and size were stabilized after 90 days after induction and these served as Breast Cancer Control (BCC) animals without any treatment. Whereas the standard group of rats received CPt injection i.v. (5.4 mg/ $\mathrm{kg}-5.67 \mathrm{mg} / \mathrm{kg}-\mathrm{CPt}$ ), test group 1 received the magnetic nanosphere coated with Vitamin C (CPtMNSVSC) at a dose of $(4.46 \mathrm{mg} / \mathrm{kg}-5.67 \mathrm{mg} / \mathrm{kg}$-CPt equivalent MNS i.v.) and the test group 2 received uncoated nanosphere in the absence of magnetic field (CPtNS) at a dose of (4.46 mg/kg-5.67 mg/kg-CPt equivalent NS i.v.) by a single iv injection through the tail vein (before injecting the tail was rubbed with xylene with a cotton in order to visualize the vein clearly).

After 90 days, all the animals were starved overnight and sacrificed by cervical decapitation. The breast tumour was surgically dissected out; from the breast cancer controls, as well as the experimental groups were investigated for histopathology study of breast tissues. The antitumor efficacy of the nanosphere formulation-test 1 (F-3 formulation in presence of a magnetic field), test 2 (F-6 formulation in the absence of magnetic field) and standard (free $\mathrm{CPt}$ ) was evaluated based on the changes in tumour volume ( $\mathrm{mm}$ in diameter) and the \% tumour inhibiting activity. ${ }^{49-51}$

$\%$ tumor inhibiting activity

$$
=100-\frac{\text { Average tumor volume of the treated group }}{\text { Average tumor volume of the control }} \times 100
$$

\section{RESULTS AND DISCUSSION}

Super-magnetically modulated nanosphere of $\mathrm{CPt}$ capped with vitamin $C$ and uncapped nanosphere of CPt were developed and evaluated for their use as a targeted drug delivery system. Several studies were conducted in the past by the researchers at formulating 
and designing efficient drug delivery systems to counter cancerous cells. This super-magnetically modulated nanopshere is considered being a potential candidate to counter the disease with the utmost clinical safety and efficacy. However, the important challenge in the successful delivery of polymeric drug delivery system is a capability of encapsulating the active ingredient within its structure and later delivers the active form to the cancerous tissue. The performance of the formulation in vivo depends significantly on the in vitro performance of the developed drug delivery system and thus in vitro characterization of the drug loaded capped nanosphere becomes essential.

Preformulation study was carried out by analysing the FTIR spectrum of physical mixtures. To assess the compatibility of $\mathrm{CPt}$ with ethyl cellulose, magnetite and vitamin $\mathrm{C}$, FTIR spectrum of pure drug $(\mathrm{CPt})$, vitamin C, magnetite, ethyl cellulose MNS, ethyl cellulose with drug and coated with vitamin $\mathrm{C}$ were recorded. The principal peak of CPt was found at wave number 3499 $\mathrm{cm}^{-1}$ which correspond to N-H stretching frequency of amino groups, wave number $1785 \mathrm{~cm}^{-1}$ showed the presence of carbonyl function. Characteristic peaks at $2853 \mathrm{~cm}^{-1}$ and $\mathrm{C}=\mathrm{O}$ absorption at $2877 \mathrm{~cm}^{-1}$ corresponds to aliphatic $\mathrm{C}-\mathrm{H}$ vibrations. The peaks observed for magnetite showed at $602 \mathrm{~cm}^{-1}$ and $663 \mathrm{~cm}^{-1}$ were the same even after formulating MNS. From the FTIR spectrum of ascorbic acid, it was confirmed that the drug is absent and an absorption peak was found at $3066 \mathrm{~cm}^{-1}$ and $2881 \mathrm{~cm}^{-1}$ indicates $\mathrm{C}-\mathrm{H}$ stretching and $1052 \mathrm{~cm}^{-1}$ indicated $\mathrm{C}-\mathrm{O}$ stretching present in vitamin C. From the FTIR spectrum of ethyl cellulose, polymer absorption peak was found at $3038 \mathrm{~cm}^{-1}$ and 2881 $\mathrm{cm}^{-1}$ indicated $\mathrm{C}-\mathrm{H}$ stretching and $1052 \mathrm{~cm}^{-1}$ indicated C-O stretching present in polymer whereas IR spectra of ethyl cellulose with drug and coated with vitamin $\mathrm{C}$ showed an absorption peak at $1052 \mathrm{~cm}^{-1}$ indicated the presence of $\mathrm{C}-\mathrm{O}$ confirmed there is no interaction between drug and polymer and absorption peak at 1235 $\mathrm{cm}^{-1}$ indicated the presence of $\mathrm{C}-\mathrm{O}$ and $3114 \mathrm{~cm}^{-1}$ indicates $\mathrm{N}-\mathrm{H}$ stretching that confirmed that the interaction between drug and polymer was nil. FTIR spectra of $\mathrm{CPt}$, excipients and formulation are depicted in Figure 2 . From the above results it was confirmed that the drug and excipients showed all the characteristic peaks of the Cpt without showing any interaction between drug and excipients and therefore they are suitable for the formulation of CPtNS and CPtMNSVC. In this study emulsion-solvent evaporation technique was followed to prepare the nanosphere because of the relative simplicity and reproducibility of the method. Solvent evaporation involves in the emulsification of polymer which showed that the maximum acetone was rapidly dispersed into the liquid paraffin and was removed from the system within the few min. This phenomenon happened because acetone is sparingly soluble in liquid paraffin and therefore slowly evaporated. Once the temperature began to rise at a constant rate, acetone started evaporating at a faster rate. Solvent evaporation profile illustrated that the constant rate of change of temperature was found to be useful in achieving a precisely controlled solvent evaporation rate..$^{52,53}$ The parameters such as evaporation temperature, rate of evaporation and rate of stirring can play a pivotal role in controlling the size of the particle.

Nanosphere of formulation F1, F2, F3, F4, F5 and F6 were prepared with different drug: polymer concentrations of 1:1,1:2 and 1:3 capped and uncapped with vitamin C, respectively (Table 1). Drug content was obtained from all the batches of CPtNS from the initial amount of drug $(15 \mathrm{mg})$ added in each batch and was used to calculate the drug entrapment efficiency. The $\%$ drug entrapment efficiency was found to be between $31.13 \pm 1.51$ to $88.93 \pm 0.77$. The results clearly suggested that the high polymer concentration lead to a high \% drug entrapment efficiency and a low polymer concentration lead to a less \% drug entrapment efficiency. The $\%$ drug entrapment efficiency was evaluated to be in the range of satisfactory to good and the good range was achieved by increasing the polymer ratio. The degree of the partition of the drug in the polymer solution phase, determines the amount of drug entrapped in nanosphere that is potentially depended on the preparation by the emulsion and evaporation method. ${ }^{54} \mathrm{It}$ was reported in the literature that the decrease in the amount of polymers may produce droplets with lesser viscosity polymer phase in the emulsion process, which may lead to migration of drug to the outer part of the nanosphere or even to the external phase during the evaporation process. Consequently, a high polymer concentration may lead to a relatively high drug loading and a low polymer concentration is likely to produce nanosphere with relatively low drug loading. ${ }^{55}$ Another important reason behind the high entrapment with the higher ratio of polymer is due to the precipitative nature of ethyl cellulose which tends to precipitate fastly in the continuous phase. Results of drug contents, \% drug entrapment efficiency, \% magnetite entrapment and particle size analysis were given in Table 3.

The particle size analysis of the sonicated CPtNS and CPtMNSVC was determined using a Malvern zeta sizer instrument. The particle size of the CPtNS and CPtMNSVC ranging from $125 \mathrm{~nm}-195 \mathrm{~nm}$ with the mean particle size being $150 \mathrm{~nm}$. Particle size plays a pivotal 
role in the overall performance of the formulation in vivo as it can directly affect the physical stability, cellular uptake, bio-distribution and drug release from the nanospheres. ${ }^{56,57}$ Another important observation was made here coating of nanosphere significantly enhances the size of the nanosphere $(p<0.05)$ (Table 3$)$. The PDI value of the F3 formulation was found to be 0.281 which is considered being an ideal and monodisperse. The amount of magnetite content per $10 \mathrm{mg}$ of nanospheres was determined from the formulation (F1-F3),
Table 3 shows the result of the magnetite content in each formulation. It was observed that entrapment of magnetite increased with the increase in the concentration of polymer added in consecutive formulations. The maximum magnetite content was found in F-3.

SEM imaging was found to be quite useful as it differentiated the coated nanosphere with uncoated nanosphere. Figure 3A clearly showed a rough appearance of uncoated nanosphere and Figure 3B showed a smooth appearance of coated nanosphere which was evident

\begin{tabular}{|c|c|c|c|c|c|}
\hline Formulation code & $\begin{array}{l}\text { Drug: polymer } \\
\text { ratio }\end{array}$ & $\begin{array}{l}\text { Drug } \\
\text { (mg) }\end{array}$ & $\begin{array}{l}\text { Polymer } \\
\text { (mg) }\end{array}$ & $\begin{array}{c}\mathrm{Fe}_{2} \mathrm{O}_{3} \\
(30 \% \mathrm{w} / \mathrm{w} \text { of polymer) } \\
\text { (mg) }\end{array}$ & $\begin{array}{c}\text { Vitamin C } \\
(\mathrm{mg})\end{array}$ \\
\hline F1 & $1: 1$ & 15 & 15 & 4.5 & 10 \\
\hline $\mathrm{F} 2$ & $1: 2$ & 15 & 30 & 9 & 10 \\
\hline F3 & $1: 3$ & 15 & 45 & 13.5 & 10 \\
\hline $\mathrm{F} 4$ & $1: 1$ & 15 & 15 & - & - \\
\hline F5 & $1: 2$ & 15 & 30 & - & - \\
\hline F6 & $1: 3$ & 15 & 45 & - & - \\
\hline
\end{tabular}

Table 2: Tumour inductions with evaluated parameters.

\begin{tabular}{|c|c|}
\hline S.No. Characterization & Noted parameters \\
\hline 1. Latency period & Appearance of $1^{\text {st }}$ tumour time \\
\hline 2. Tumour incidence & Number of rats with tumour \\
\hline 3. Tumour burden & Number of tumour per rat \\
\hline 4. Total tumour volume & Per no.of animals in each group \\
\hline 5. Tumour multiplicity & No. of tumours per rat \\
\hline 6. Estimated tumour weight (ETW) & larger diameter $\times$ (shorter diameter)2/2mg \\
\hline \multirow[t]{4}{*}{ 8. Tumour doubling time } & $(\mathrm{Td} 1)=\mathrm{t} \ln 1 / 2(\ln \mathrm{V} 1-\ln \mathrm{Vo})$ \\
\hline & $\mathrm{t}=$ time of tumour appearance \\
\hline & V1=ETW 90 days after DMBA administration \\
\hline & Vo=ETW at the time of tumour appeared \\
\hline $\begin{array}{l}\text { 9. Width and length of the tumour was measured weekly to } \\
\text { determine tumour volume }\end{array}$ & $V(\mathrm{~mm} 3)=[($ width $) 2+$ (length $)] / 2$ \\
\hline
\end{tabular}

\begin{tabular}{|c|c|c|c|c|c|c|}
\multicolumn{6}{|c|}{ Table 3: Results of drug contents, \% entrapment efficiency, mean particle size and \% magnetic } \\
responsiveness.
\end{tabular}

Values are expressed as mean $\pm \operatorname{SEM}(n=3)$ 
from the SEM images. SEM images were used to evaluate the topography of nanosphere which clearly differentiated from rough to a smooth surface. ${ }^{35}$ The water swelling kinetics of the prepared magnetic nanosphere was measured at room temperature. The samples swelled and reached equilibrium at room temperature in the $8 \mathrm{hr}$. In the first hour, the swelling kinetic was found to be 0.2785 and saturated at the $8^{\text {th }} \mathrm{hr}$ with the value 0.3235 and 0.3236 in the $6^{\text {th }}$ and $8^{\text {th }} \mathrm{hr}$, respectively. Swelling kinetics and SEM were basically carried out to support the drug release mechanism. ${ }^{58}$

DSC thermograms of pure drug $(\mathrm{CPt})$, polymer (ethyl cellulose) and coated formulation (F3) were analysed to detect the phenomenon of interactions if any. The curves of the DSC are shown in Figure 4. DSC thermogram of $\mathrm{CPt}$ (Figure 4A) exhibited endothermic peaks at $107.23^{\circ} \mathrm{C}$ which eventually corresponds to the melting temperature (Tm) of carboplatin. The DSC thermogram of ethyl cellulose (Figure 4B) exhibited an endothermic peak at $114.60^{\circ} \mathrm{C}$ which corresponds to its melting temperature ( $\mathrm{Tm})$. The thermogram of formulation F3 (Figure 4C) showed endothermic peaks at $155.76^{\circ} \mathrm{C}$ and $167.76^{\circ} \mathrm{C}$ and did not show any significant shift in peaks compared to that of $\mathrm{CPt}$ and ethyl cellulose. The compatibility between the pure drug and the excipients was confirmed by DSC results which indicated no significant interactions in the formulation. The percentage of the nanosphere failed to remain in the glass tube in the absence and presence of a magnetic field was compared. Formulations (F1-F6) were sub-

\begin{tabular}{|c|c|c|c|}
\hline \multicolumn{3}{|c|}{ Table 4: Average tumor volume of different animal } \\
groups. \\
\hline $\begin{array}{c}\text { S. } \\
\text { No. }\end{array}$ & Animal groups & $\begin{array}{c}\text { Average } \\
\text { tumour } \\
\text { volume }\left(\mathrm{mm}^{3}\right)\end{array}$ & $\begin{array}{c}\text { Increase in } \\
\text { tumour volume } \\
\text { (\%) }\end{array}$ \\
\hline 1 & BCC & 62.14 & 100.00 \\
\hline 2 & $\begin{array}{c}\text { BCC+ standard } \\
\text { (free CPt) }\end{array}$ & $48.32^{* *}$ & 77.78 \\
\hline 3 & BCC+F-6 MNS & $22.00^{* *}$ & 35.41 \\
\hline 4 & BCC+F-3 MNSVC & $16.00^{* *}$ & 25.75 \\
\hline
\end{tabular}

The values are expressed as Mean $\pm \mathrm{SEM}, n=6$ rats in one group. $* * P<0.01$ highly significant when compared with BCC.

\begin{tabular}{|c|c|c|}
\hline S.No & Animal groups & $\begin{array}{l}\text { \% Tumour } \\
\text { inhibition }\end{array}$ \\
\hline 1. & $\mathrm{BCC}$ & 00.00 \\
\hline 2. & $\mathrm{BCC}+$ standard (free CPt) & 22.22 \\
\hline 3. & $\mathrm{BCC}+\mathrm{F}-6 \mathrm{MNS}$ & 54.25 \\
\hline 4. & $\mathrm{BCC}+\mathrm{F}-3$ MNSVC & 74.59 \\
\hline
\end{tabular}

jected to the magnetic responsiveness test and Figure 5 showed the result of magnetic responsiveness. The magnetic responsiveness, after $15 \mathrm{~min}$ was found to be highest $90.57 \pm 0.54 \%$ for formulation F-3 and least $61.12 \pm 1.63 \%$ for formulation F-1 under the influence of magnetic field. It was observed that the majority of the nanospheres in 0.21 kilogauss (from a distance of 3 $\mathrm{cm}$ ) magnetic field and in a flow rate equal to $0.5 \mathrm{~cm} / \mathrm{s}$ was retained and did not exit the glass tube. The magnetic responsiveness was found to be increased with the increase in entrapped magnetite content and irrespective of the increase in the concentration of polymers. In the presence of a magnetic field, the retention of nanospheres was significantly high $(p<0.05)$ compared to the absence of a magnetic field. Therefore, it was predicted that the super magnetically modulated nanospheres can accumulate in the capillaries following in vivo administration. Magnetic targeting of the nanospheres was developed to overcome the two major problems encountered in drug targeting, such as poor stability in the reticuloendothelial system and limited target site specificity. ${ }^{59} \mathrm{Vita}-$ min $C$ was aimed to coat the magnetic nanosphere to serve a dual purpose of increasing the circulation time of MNS in vivo and manifest antioxidant activity to synergize the therapy.$^{60}$ Therefore, this study was conducted to evaluate and measure the antioxidant properties of vitamin $\mathrm{C}$ after coating. The in vitro antioxidant activity of CPtMNSVC was evaluated as free radical scavenging

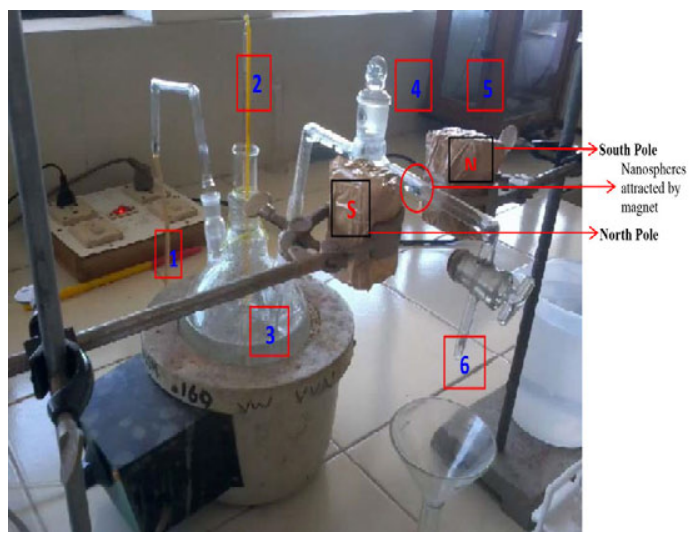

Figure 1: Special apparatus to conduct in vitro magnetic responsiveness. Connection to pump (1), thermometer (2), PBS $7.4 \mathrm{pH}(3)$, injection site (4), magnet (5), collecting sample (6).

\begin{tabular}{|c|c|c|}
\hline S. No. & Parameters & Observation \\
\hline 1. & Latency period (day) & 27.00 \\
\hline 2. & $\begin{array}{l}\text { Tumour burden (tumour/ } \\
\text { rats) }\end{array}$ & 1.33 \\
\hline 3. & Tumour incidence (\%) & 83.00 \\
\hline 4. & Tumour doubling time (day) & 32.00 \\
\hline
\end{tabular}




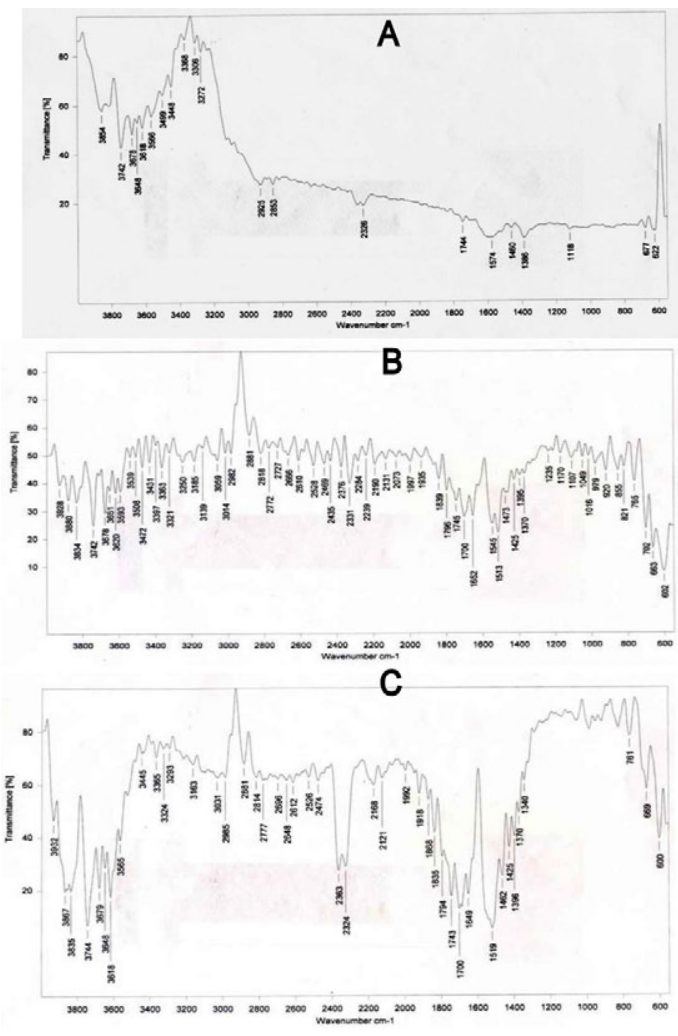

Figure 2: IR spectra of Carboplatin (A), magnetite (B) and formulation (C).

activity ( $\%$ of DPPH scavenged). The $\%$ inhibition of DPPH by CPtMNSVC was compared with $\%$ inhibition of DPPH by standard (Ascorbic acid) at $10-50 \mu \mathrm{g} / \mathrm{mL}$ concentrations. The $\%$ inhibition of DPPH at $50 \mu \mathrm{g} /$ $\mathrm{mL}$ concentration by ascorbic acid and CPtMNSVC was found to be $85.75 \pm 2.51 \%$ and $60.53 \pm 1.13 \%$, respectively, the results are depicted in Figure 6. The obtained findings of the in vitro experiment indicated that vitamin $\mathrm{C}$ possesses good antioxidant free radical scavenging activity even when used at low concentrations. Vitamin C in CPtMNSVC in a concentration of $15 \% \mathrm{w} / \mathrm{w}$ showed good antioxidant free radical-scavenging activity and, consequently, it may have good protection and healing action against the cancerous cell. ${ }^{61}$ The administration of vitamin $\mathrm{C}$ as a coating agent considered as an impregnable substitute for its use.

The in vitro release study was carried out for all the prepared batches and the results are displayed in Figure 7. Biphasic behaviour was observed for the formulation F4, F5 and F6, which displayed initial burst release ( $45 \%$ in $4 \mathrm{~h}$ ) followed by sustained release $(85 \%)$ over a period of $24 \mathrm{hr}$. The initial burst release of drug was seen probably due to the release of CPt that was loosely bound or adsorbed on the surface of the nanosphere. On the other side, formulations F1, F2 and F3 did not display burst release ( $45 \%$ in $4 \mathrm{hr}$ ) but showed sustained

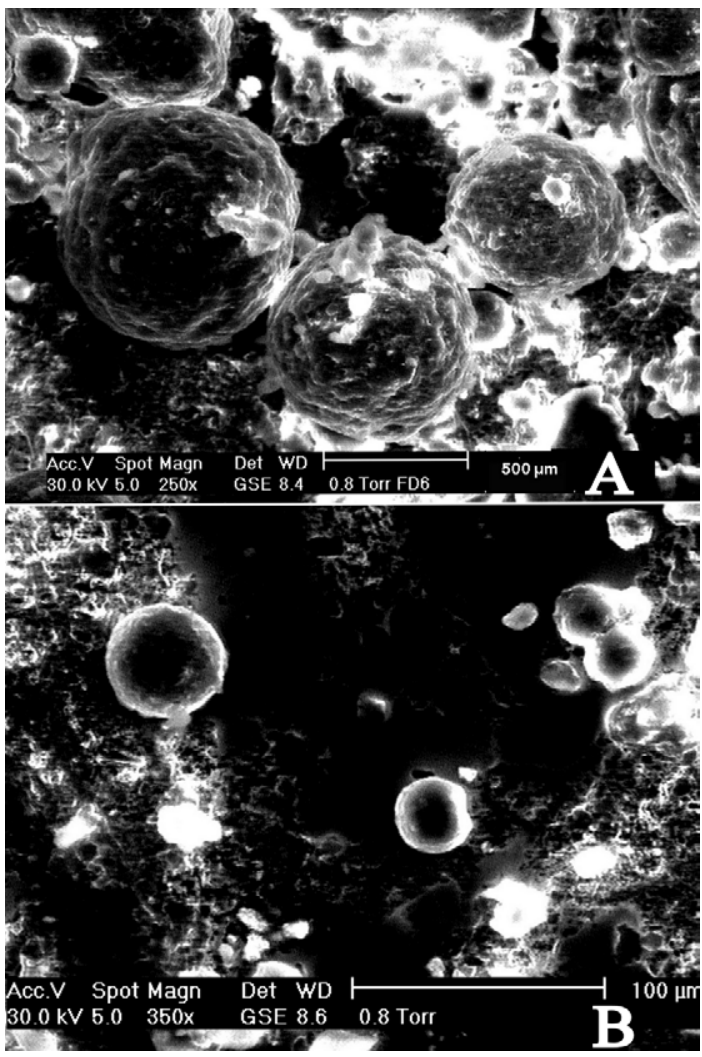

Figure 3: SEM photograph of coated nanosphere $(A)$ and uncoated nanosphere (B).
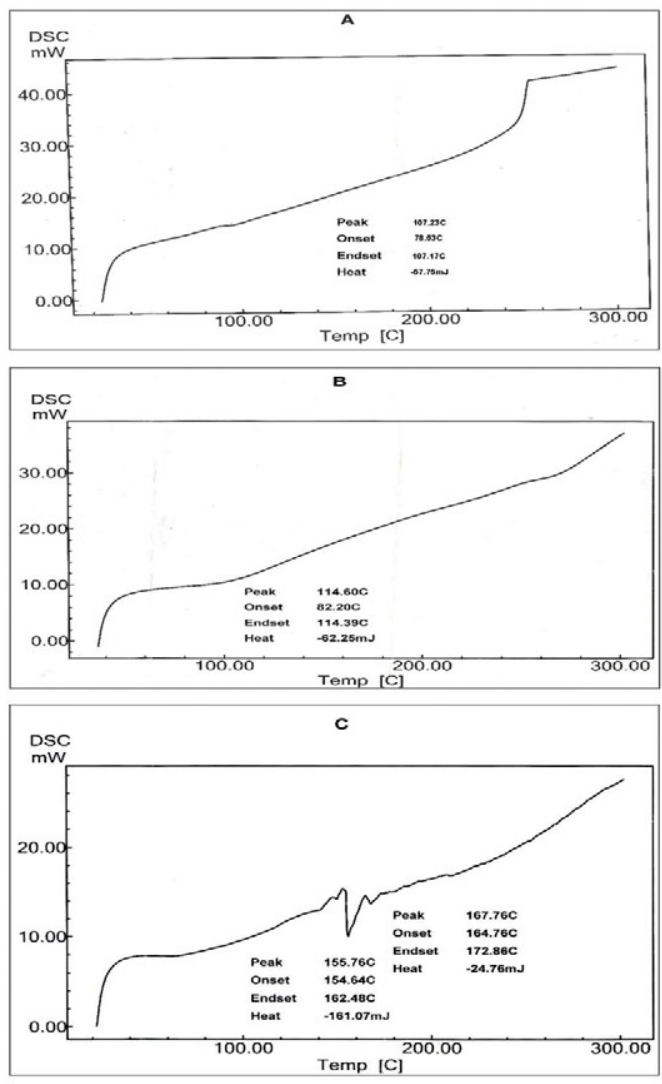

Figure 4: DSC thermogram of $\mathrm{CPt}(\mathrm{A})$, ethyl cellulose (B) and formulation $\mathrm{F} 3(\mathrm{C})$. 
release $(90 \%$ in $24 \mathrm{hr}$ ) that may be due to slow diffusion of the drug from the polymer matrix. Biphasic behaviour was not observed in the formulation F1, F2 and F3 probably due to vitamin $\mathrm{C}$ coating, that was confirmed by SEM. Another observation was made in the drug release study was with the low concentration of ethyl cellulose, release of carboplatin was found to be swift than those with a higher concentration of ethyl cellulose. ${ }^{62}$ An increase in the concentration of polymer probably leads to the formation of a bushy and slighter porous polymer matrix. The in vitro release of vitamin $\mathrm{C}$ from F1, F2 and F3 was swift and almost $80 \%$ of vitamin $\mathrm{C}$ released after $10 \mathrm{hr}$. Such a result was recorded probably happened due to the solubilisation of vitamin $\mathrm{C}$ in the medium which eventually not entrapped in the polymers but coated around the nanophere. The coating of the nanosphere constrains the burst release of carboplatin, which was not observed in the F4, F5 and F6 batches. The release of CPt from MNS is not likely to be a dissolution-controlled mechanism because $\mathrm{CPt}$ is water soluble and has poor solubility in the polymers. The release of CPt during this period could be attributed to the diffusion from the MNS through the pores and channels on and close to the surface of the nanosphere. From the result, it is apparent that maximum linearity from the plot and high correlation value from Higuchi diffusion model suggested carboplatin release followed diffusion controlled mechanism. The data were fit to Korsmeyer et al. equation and slope (n) values were obtained indicated that the drug release deviates slightly from fickian trend following an anomalous or non-fickian trend. To evaluate the mechanism of drug release, initial $60 \%$ of the cumulative drug release data were fitted as Korsemeyer-Peppas is valid upto $60 \%$ cumulative drug release. ${ }^{43,44}$ The value of release exponent (n) was found to be 0.5432 where $\mathrm{n}$ value is $>0.5$ suggested non-fickian diffusion (diffusion coupled with erosion). ${ }^{63}$

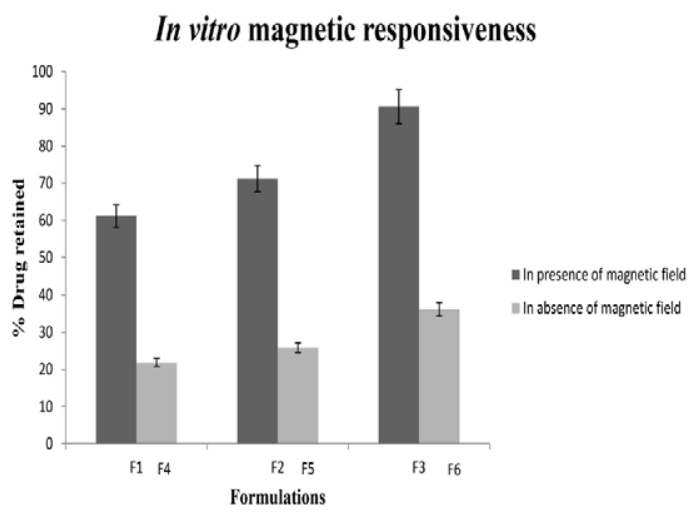

Figure 5: In vitro magnetic responsiveness of magnetic microspheres in presence and absence of magnetic field. Values are expressed in mean $\pm \operatorname{SEM}(n=3)$.
The formation of the pores and channels initially due to the early release of the drug which was located on and close to the surface of the nanosphere. With the penetration of release medium through the pores, the drug was dissolved in the medium and diffused out of the microspheres through the aqueous channels. As the channels formed deeper into the nanosphere, more amount of drug was released. Meanwhile, the polymer matrix gradually breaks down by hydrolytic cleavages and the matrix permeability increases with time..$^{64,65}$

Concerning the methodology, the present in vivo study was conducted to assess the impact of the presence and absence of a magnetic field with or without capping of Vitamin $C$ and compared. The average tumour volume of different animal groups was given in Table 4, which showed that 3.88-folds increased tumour volume of BCC rats during 45 days of the treatment. When compared with $\mathrm{CPt}$ solution, the tumour volume of BCC rats was found to be raised by 3.02 fold. Most significantly, tumour growth was suppressed in the group which received F-3 (CPtMNSVC) in the presence of a magnetic field compared to F-6 (CPtNS) in the absence

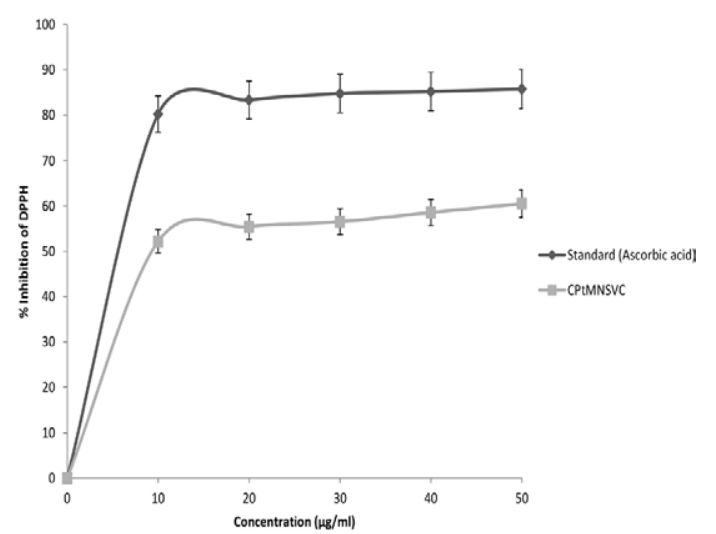

Figure 6: \% Inhibition of DPPH by standard (Ascorbic acid) and CPtMNSVC. Values are expressed in mean \pm SEM $(n=3)$.

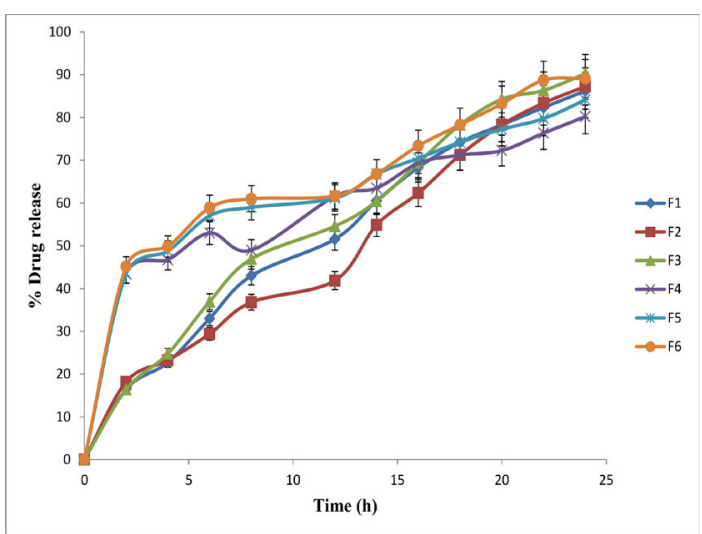

Figure 7: In vitro drug release profile of all formulations. Values are expressed in mean $\pm \operatorname{SEM}(n=3)$. 
of a magnetic field. In Figure 8A BCC group rat showing excessive tumour metastasis, whereas in Figure 8B the tumour induced rat treated with standard free $\mathrm{CPt}$ showed less metastasis without decrease in tumour volume. Another observation was made herein with the F-6 (CPtNS) formulation in the absence of a magnetic field showed the absence of metastasis with decreased volume in the rats and the result is displayed in Figure 8C. The crucial observation was made herein with the F-3 (CptMNSVC) in the presence of a magnetic field showed the absence of metastasis with a significant decrease in tumour volume. (Figure 8D).

Another observation was made when rats were treated with F-3 (CptMNSVC) in the presence of magnetic field and showed a 1.15-fold increase in tumour inhibiting activity confirming that CptMNSVC showed better tumour inhibiting activity in the presence of external magnetic field applied in comparison with rats treated with CPtNS in the absence of externally applied magnetic field. (Table 5) These observations were confirmed by pairwise statistical comparison test which indicated that, compared to BCC group, the relative tumour volume of the animals that received $\mathrm{CPt}$ solution, F-6 (CPtNS) in presence and absence of magnetic field applied were significantly different $(P<0.05)$.

Before initiating the histopathological study of rat, we examined the various evaluated parameters during in vivo studies such as latency period (day), tumour bur-

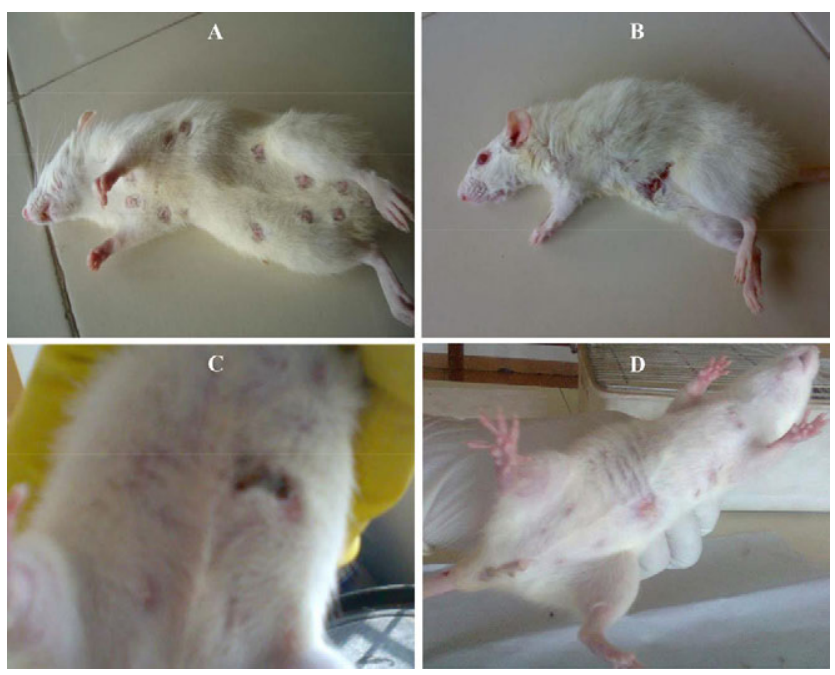

Figure 8: Tumour induced and treated rats: Breast Cancer Control Group showing excessive tumour metastasis (A), tumour induced rat treated with standard free CPt showing less metastasis with no decrease in tumour volume (B), tumour induced rat treated with the F- 6 NS formulation in absence of magnetic field showing absence of metastasis with decreased tumour volume (C), tumour induced rat treated with the F-3 (MNSVC) formulation in presence of magnetic field showing absence of metastasis with a significant decrease in tumour volume (D). den (tumour/rats), tumour incidence (\%) and tumour doubling time (day) and the results are shown in Table 6. A $10-14 \%$ increase in the mean body weight of all the group animals were recorded throughout the study. However, a statistically significant difference in the body weights of the rats was observed between the groups neither before treatment nor when euthanized.

Histopathological analysis of rats in BCC group tissues mainly showed a significant progression of muscle mass, skin and adipose tissue. Tumour mass was appeared and consists of spindle cells which were arranged in an irregular pattern and appeared to be malignant. Closer to the tumour mass, a well-defined epithelial tumour is noted showed ductal proliferation, which suggested being adenoma and spindle cell sarcoma Figure 9A. The animals treated with the pure drug solution of $\mathrm{CPt}$, tissue section showed skin epithelium, hair follicles and small foci of cartilage, fatty tissue, skeletal muscles and tumour mass. Tumour mass mainly consists of spindleshaped cells arranged in fascicles showed features of malignancy like pleomorphism, abnormal mitosis; few tumour giant cells were also seen. The tumour is also infiltrating adjacent muscles and the impression of the slide suggested aggressive spindle cell sarcoma depicted

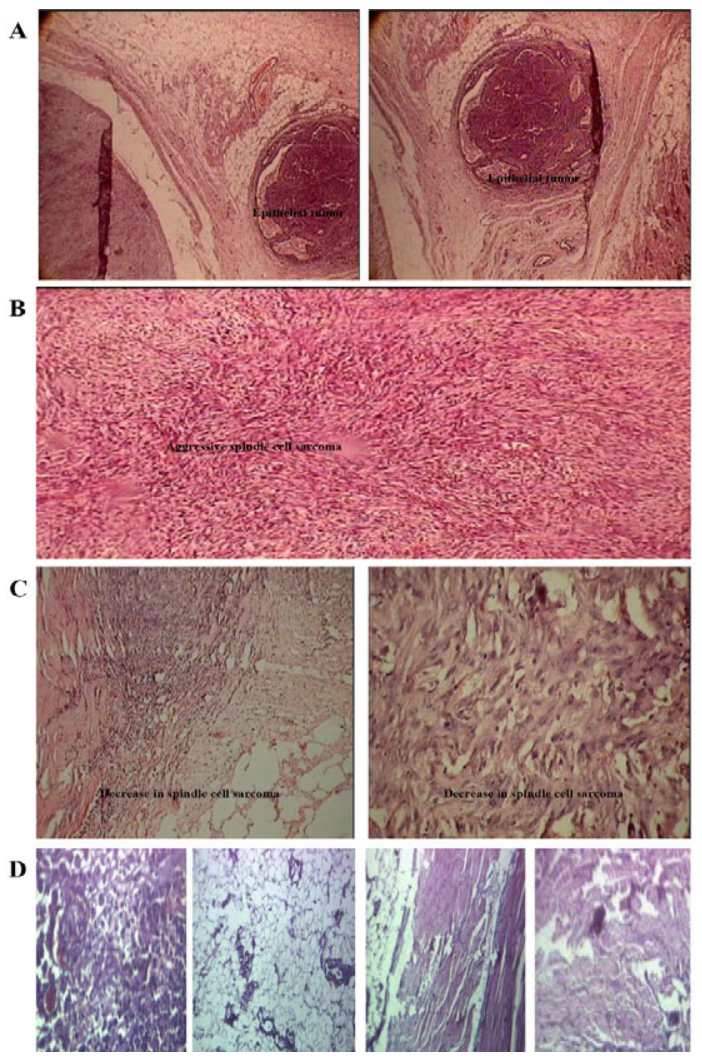

Figure 9: Histopathology of BCC rat tissue (A), pure drug solution treated rat tissue (B), F-6 NS treated rat tissue in absence of magnetic field (C) and F-3 (MNSVC) treated rat tissue in presence of magnetic field (D). 
in Figure 9B. The animals treated with the F-6 (CPtNS) in the absence of magnetic field tissue sections showed muscle, fibrous connective tissue and a small portion of adipose tissue. A part of connective tissue showed tumour mass, consisting of sheets of spindle-shaped cells showed features of malignancy like pleomorphism and increased and abnormal mitosis is noted. Connective tissue has also shown infiltration with chronic inflammatory cells. The impression of this slide suggested spindle cell sarcoma decreases comparatively from the first slide and the result is displayed in Figure 9C. The animals treated with the F-3 (CPtMNSVC) in the presence of magnetic field tissue sections mainly showed muscle mass, skin and adipose tissue. Tumour mass arrangement of spindle cells in the irregular pattern is significantly absent and these cells were free from malignancy/ carcinoma. A portion of connective tissue showed a significant reduction of the tumour mass, absence of spindle-shaped cells without any features of malignancy like pleomorphism and increased and abnormal mitosis. Connective tissue has also demonstrated a lack of infiltration with chronic inflammatory cells. (Figure 9D).

Histopathological results indicated that the F-3 (CPtMNSVC) in the presence of the magnetic field had effectively suppressed the breast cancer induced by the DMBA. Therefore contrary to conventional therapy, super-magnetically modulated novel parenteral carrier capped with vitamin $\mathrm{C}$ can specially target tumours with the reduced after effects and toxicity after bypassing p-glycoprotein associated drug resistance mechanism leading to better efficacy. ${ }^{66-68}$ Nanosphere formed by loading carboplatin and capped with vitamin $\mathrm{C}$ was found to be efficiently internalized by cells and showed toxicity to cancerous cells, which was considered to be dose-dependent cytotoxicity. Coating of vitamin C enhanced the circulation of nanosphere and thus lead to sufficient accumulation in tumour tissues and this finding followed the Akbarzadeh A et al. in which modified magnetic nanoparticle increased circulation time. ${ }^{69}$ Since vitamin $\mathrm{C}$ is an antioxidant and can play a vital role in collagen synthesis; therefore, its antioxidant ability was also assessed in vivo. It was apparent from the histopathological result that vitamin $\mathrm{C}$ coat enhanced the circulation time of nanosphere, thereby demonstrated better target ability by curbing the growth of the tumour with the mutation..$^{70,71}$

\section{CONCLUSION}

The present study concluded that ethyl cellulose is a suitable and compatible biodegradable polymer for preparing magnetically responsive nanosphere of CPt. Vitamin C capping helped to enhance the circulation time, increase the target ability of magnetic particles and synergize the impact of carboplatin with the antioxidant effect. The results of in vitro characterization of the developed carboplatin nanosphere were found to be ideal. Magnetic field strength and gradient, distribution of the magnetite in the nanosphere, application time of the magnetic field and in vitro-in vivo co-relationship under diseased state were successfully established. Hence, the current study was found to be a satisfactory preliminary attempt for the development of a supermagnetically modulated novel parenteral carrier of carboplatin capped with the vitamin $C$ and opens up new vistas in cancer treatment.

\section{ACKNOWLEDGEMENT}

The authors wish to acknowledge the NGSM Institute of Pharmaceutical Sciences, Nitte (Deemed to be University), Mangaluru, India and National Institute of Technology Karnataka, Mangaluru, India for providing necessary facilities and financial support to carry out this project. The authors dedicated this research work to the beloved professor Late Dr. Prabhakara Prabhu (deceased on 26/11/2018) as he was the esteemed guide of the conducted work and also for his immense contribution to the research in the area of advanced drug delivery systems.

\section{CONFLICT OF INTEREST}

The authors declare no conflict of interest.

\section{ABBREVIATIONS}

MNS: Magnetic Nanosphere; CPt: Carboplatin; MNSVC: Magnetic nanosphere with Vitamin C; CPtNS: Carboplatin nanosphere; CPtMNSVC: Carboplatin magnetic nanosphere coated with Vitamin C; PDI: Poly dispersibility index; SR: Swelling ratio; FTIR: Fourier -transform infrared spectroscopy; SEM: Scanning electron microscopy; DSC: Differential scanning calorimetry.

\section{REFERENCES}

1. Siegel RL, Miller KD, Jemal A. Cancer statistics, 2018. CA Cancer J Clin. 2018;68(1):7-30.

2. Sun YS, Zhao Z, Yang ZN, Xu F, Lu HJ, et al. Risk factors and preventions of breast cancer. Int J Biol Sci. 2017;13(11):1387-97.

3. Chopra D, Rehan HS, Sharma V, Mishra R. Chemotherapy-induced adverse drug reactions in oncology patients: A prospective observational survey. Indian J Med Paediatr Oncol. 2016;37(1):42-6.

4. Steward WP, Brown K. Cancer chemoprevention: A rapidly evolving field. $\mathrm{Br}$ J Cancer. 2013;109(1):1-7.

5. Marszałł MP. Application of magnetic nanoparticles in pharmaceutical sciences. Pharm Res. 2011;28(3):480-3. 
6. Revia RA, Zhang M. Magnetite nanoparticles for cancer diagnosis, treatment and treatment monitoring: Recent advances. Mater Today. 2016;19(3):15768.

7. Malik A, Butt TT, Zahid S, Zahid F, Waquar S, Rasool M, et al. Use of magnetic nanoparticles as targeted therapy: Theranostic approach to treat and diagnose cancer. J Nanotechnol. 2017;2017:1098765.

8. Shen SX, Wang GZ, Hong X, Zhu W. Nanospheres of silver nanoparticles: Agglomeration, surface morphology control and application as SERS substrates. Phy Chem Chem Phys. 2009;11(34):7450-4.

9. Jiang QL, Zheng SW, Hong RY, Deng SM, Guo L, Hu RL, et al. Folic acidconjugated $\mathrm{Fe}_{3} \mathrm{O}_{4}$ magnetic nanoparticles for hyperthermia and MRI in vitro and in vivo. Appl Surf Sci. 2014;307:224-33.

10. Arruebo M, Fernández-Pacheco R, Ibarra MR, Santamaría J. Magnetic nanoparticles for drug delivery. Nano Today. 2007;2(3):22-32.

11. Bulte JW, Douglas T, Mann S, Frankel RB, Moskowitz BM, Brooks RA, et al. Magnetoferritin: Characterization of a novel superparamagnetic MR contrast agent. J Magn Reson Imaging. 1994;4(3):497-505.

12. Colombo M, Carregal-Romero S, Casula MF, Colombo M, Carregal-Romero $\mathrm{S}$, Casula MF, et al. Biological applications of magnetic nanoparticles. Chem Soc Rev. 2012;41(11):4306-34.

13. Dong $X$, Mumper RJ. Nanomedicinal strategies to treat multidrug-resistant tumors: Current progress. Nanomedicine. 2010;5(4):597-615.

14. Kadam CY, Abhang SA. Apoptosis markers in breast cancer therapy. Adv Clin Chem. 2016;74:143-93.

15. Dunton $\mathrm{CJ}$. Management of treatment-related toxicity in advanced ovarian cancer. Oncologist. 2002;7(Supplement 5):11-9.

16. Cook JD, Reddy MB. Effect of ascorbic acid intake on nonheme-iron absorption from a complete diet. Am J Clin Nutr. 2001;73(1):93-8.

17. Hoshyar N, Gray S, Han H, Bao G. The effect of nanoparticle size on in vivo pharmacokinetics and cellular interaction. Nanomedicine. 2016;11(6):673-92.

18. Frei B, Lawson S. Vitamin C and cancer revisited. Proc Natl Acad Sci. 2008;105(32):11037-8.

19. Sies H. Vitamin C: Its chemistry and biochemistry. Angew Chemie. 1992;104:948

20. Du J, Cullen JJ, Buettner GR. Ascorbic acid: Chemistry, biology and the treatment of cancer. Biochim Biophys Acta. 2012;1826(2):443-57.

21. Faraji M, Yamini $Y$, Rezaee $M$. Magnetic nanoparticles: synthesis, stabilization, functionalization, characterization and applications. J Iran Chem Soc. 2010;7(1):1-37.

22. Xu C, Sun S. New forms of superparamagnetic nanoparticles for biomedical applications. Adv Drug Deliv Rev. 2013;65(5):732-43.

23. Sreeja V, Joy PA. Effect of inter-particle interactions on the magnetic properties of magnetite nanoparticles after coating with dextran. Int J Nanotechnol. 2011;8(10):907-15.

24. Pandav S, Naik J. Preparation and in vitro evaluation of ethylcellulose and polymethacrylate resins loaded microparticles containing hydrophilic drug. J Pharm. 2014;2014:904036.

25. Mukherji G, Murthy RSR, Miglani BD. Preparation and evaluation of cellulose nanospheres containing 5-fluorouracil. Int J Pharm. 1990:65(1-2):1-5.

26. Lu B, Zhang JQ, Yang $\mathrm{H}$. Lung-targeting microspheres of carboplatin. Int J Pharm. 2003;265(1-2):1-11.

27. Saravanan M, Vijay VA, Kumar PDP, Sushma A, Priya S, Maharajan G, et al. Comparative studies on diclofenac sodium loaded albumin/gelatin magnetic microspheres for intra-arterial administration. Acta Pharm Sci. 2008;50(3):189-95.

28. Gallarate M, Carlotti ME, Trotta M, Bovo S. On the stability of ascorbic acid in emulsified systems for topical and cosmetic use. Int $\mathrm{J}$ Pharm. 1999;188(2):233-41.

29. Sreeja V, Jayaprabha KN, Joy PA. Water-dispersible ascorbic-acid-coated magnetite nanoparticles for contrast enhancement in MRI. Appl Nanosci. 2015;5(4):435-41.

30. Pinnell SR, Yang H, Omar M, Monteiro-Riviere N, DeBuys HV, Walker LC, et al. Topical L-ascorbic acid: Percutaneous absorption studies. Dermatol Surg. 2001;27(2):137-42.

31. Miyazaki Y, Onuki Y, Yakou S, Takayama K. Effect of temperature-increase rate on drug release characteristics of dextran microspheres prepared by emulsion solvent evaporation process. Int J Pharm. 2006;324(2):144-51.
32. Fonseca C, Simões S, Gaspar R. Paclitaxel-loaded PLGA nanoparticles: Preparation, physicochemical characterization and in vitro anti-tumoral activity. J Control Release. 2002;83(2):273-86.

33. Kakar S, Batra D, Singh R. Preparation and evaluation of magnetic microspheres of mesalamine (5-aminosalicylic acid) for colon drug delivery. J Acute Dis. 2013;2(3):226-31.

34. Gayakwad SG, Bejugam NK, Akhavein N, Uddin NA, Oettinger CE, D'Souza $\mathrm{MJ}$. Formulation and in vitro characterization of spray-dried antisense oligonucleotide to NF-kappaB encapsulated albumin microspheres. J Microencapsul. 2009;26(8):692-700.

35. Seitavuopio P, Heinämäki J, Rantanen J, Yliruusi J. Monitoring tablet surface roughness during the film coating process. AAPS Pharm Sci Tech. 2006;7(2):E1-6.

36. Avivi S, Felner I, Novik I, Gedanken A. The preparation of magnetic proteinaceous microspheres using the sonochemical method. Biochim Biophys Acta. 2001;1527(3):123-9.

37. Zhou S, Sun J, Sun L, Dai Y, Liu L, Li X, et al. Preparation and characterization of interferon-loaded magnetic biodegradable microspheres. J Biomed Mater Res B Appl Biomater. 2008;87(1):189-96.

38. Barati A, Norouzi H, Sharafoddinzadeh S, Davarnejad R. Swelling kinetics modeling of cationic methacrylamide-based hydrogels. World Appl Sci J. 2010;11(11):1336-41.

39. Musumeci T, Ventura CA, Giannone I, Ruozi B, Montenegro L, Pignatello $\mathrm{R}$, et al. PLA/PLGA nanoparticles for sustained release of docetaxel. Int J Pharm. 2006;325(1-2):172-9.

40. Saravanan M, Bhaskar K, Maharajan G, Pillai KS. Ultrasonically controlled release and targeted delivery of diclofenac sodium via gelatin magnetic microspheres. Int J Pharm. 2004;283(1-2):71-82.

41. Tamizharasi S, Rathi JC, Rathi V. Formulation and Evaluation of Pentoxifylline-Loaded Poly ( $\varepsilon$-caprolactone) Microspheres. Indian J Pharm Sci. 2008;70(3):333-7.

42. Fu Y, Kao WJ. Drug release kinetics and transport mechanisms of Nondegradable and degradable polymeric delivery systems. Expert Opin Drug Deliv. 2010;7(4):429-44.

43. Kumar L, Reddy MS, Shirodkar RK, Pai GK, Krishna VT, Verma R. Preparation and characterisation of fluconazole vaginal films for the treatment of vaginal Candidiasis. Indian J Pharm Sci. 2013;75(5):585-90.

44. Dash S, Murthy PN, Nath LK, Chowdhary P. Kinetic modelling on drug release from controlled drug delivery systems. Acta Pol Pharm. 2010;67(3):217-3.

45. Liu B, Han L, Liu J, Han S, Chen Z, Jiang L. Co-delivery of paclitaxel and TOScisplatin via TAT-targeted solid lipid nanoparticles with synergistic antitumor activity against cervical cancer. Int J Nanomedicine. 2017;12:955-68.

46. Onoja SO, Omeh YN, Ezeja MI, Chukwu MN. Evaluation of the in vitro and in vivo antioxidant potentials of aframomum melegueta methanolic seed extract. J Trop Med. 2014;2014:159343.

47. Gupta PK, Hung CT, Rao NS. Ultrastructural disposition of adriamycinassociated magnetic albumin microspheres in rats. $\mathrm{J}$ Pharm Sci. 1989;78(4):290-4.

48. Gupta PK, Hung CT. Targeted delivery of low dose doxorubicin hydrochloride administered via magnetic albumin microspheres in rats. J Microencapsul. 1990;7(1):85-94.

49. Iwalewa EO, Adewale IO, Taiwo BJ, Arogundade T, Osinowo A, Oluwatoyin $\mathrm{M}$, et al. Effects of Harungana madagascariensis stem bark extract on the antioxidant markers in alloxan induced diabetic and carrageenan induced inflammatory disorders in rats. J Complement Integr Med. 2008;5(1):1088.

50. Dhar S, Kolishetti N, Lippard SJ, Farokhzad OC. Targeted delivery of a cisplatin prodrug for safer and more effective prostate cancer therapy in vivo. Proc Natl Acad Sci. 2011;108(5):1850-5.

51. Gupta PK, Hung C. Evaluation of parameters controlling the efficacy of magnetic microspheres in the targeted delivery of Adriamycin in rats. Int J Pharm. 1990;59(1):57-67.

52. Solvent Evaporation. Biomaterials science: an introduction to materials in medicine. $3^{\text {rd }}$ ed. Elsevier Inc. 2013.

53. Maravajhala V, Dasari N, Sepuri A, Joginapalli S. Design and evaluation of niacin microspheres. Indian J Pharm Sci. 2009;71(6):663-9.

54. Jones DS, Pearce KJ. Contribution of process variables to the entrapment efficiency of propranolol hydrochloride within ethylcellulose microspheres 
prepared by the solvent evaporation method as evaluated using a factorial design. Int J Pharm. 1996;131(1):25-31.

55. Mukerjee A, Vishwanatha JK. Formulation, characterization and evaluation of curcumin-loaded PLGA nanospheres for cancer therapy. Anticancer Res. 2009;29(10):3867-75.

56. Feng SS. Nanoparticles of biodegradable polymers for new-concept chemotherapy. Expert Rev Med Devices. 2004;1(1):115-25.

57. Löberg J, Holmberg JP, Mattisson I, Arvidsson A, Ahlberg E. Electronic properties of $\mathrm{TiO}_{2}$ nanoparticles films and the effect on apatite-forming ability. Int J Dent. 2013;2013:139615.

58. Sankalia JM, Sankalia MG, Mashru RC. Drug release and swelling kinetics of directly compressed glipizide sustained-release matrices: Establishment of level A IVIVC. J Control Release. 2008;129(1):49-58.

59. Yu MK, Park J, Jon S. Targeting strategies for multifunctional nanoparticles in cancer imaging and therapy. Theranostics. 2012;2(1):3-44.

60. Parhizkar E, Rashedinia M, Karimi M, Alipour S. Design and development of Vitamin C-encapsulated proliposome with improved in-vitro and ex-vivo antioxidant efficacy. J Microencapsul. 2018;35(3);301-11.

61. Hatem E, Azzi S, ElBanna N, He T, Heneman-Masurel A, Vernis L, et al. Auranofin/Vitamin C: A novel drug combination targeting triple-negative breast cancer. J Natl Cancer Inst. 2018;111(6):597-608.

62. Prasertmanakit S, Praphairaksit N, Chiangthong W, Muangsin N. Ethyl cellulose microcapsules for protecting and controlled release of folic acid. AAPS Pharm Sci Tech. 2009;10(4):1104-12.

63. Peppas NA. Analysis of Fickian and non-Fickian drug release from polymers. Pharm Acta Helv 1985;60:110-1.

64. Kotwal VB, Saifee M, Inamdar M, Bhise K. Biodegradable polymers: Which, when and why?. Indian J Pharm Sci. 2007;69(5):616-25.

65. Marin E, Briceño MI, Caballero-George C. Critical evaluation of biodegradable polymers used in nanodrugs. Int J Nanomedicine. 2013;8:3071-90.

66. Golla K, Cherukuvada B, Ahmed F, Kondapi AK. Efficacy, safety and anticancer activity of protein nanoparticle-based delivery of doxorubicin through intravenous administration in rats. PLoS One. 2012;7(12):e51960.

67. Sadhukha T, Prabha S. Encapsulation in nanoparticles improves anti-cancer efficacy of carboplatin. AAPS Pharm Sci Tech. 2014;15(4):1029-38.

68. Wahajuddin AS. Superparamagnetic iron oxide nanoparticles: Magnetic nanoplatforms as drug carriers. Int J Nanomedicine. 2012;7:3445-71.

69. Akbarzadeh A, Mikaeili H, Zarghami N, Mohammad R, Barkhordari A, Davaran S. Preparation and in vitro evaluation of doxorubicin-loaded $\mathrm{Fe}_{3} \mathrm{O}_{4}$ magnetic nanoparticles modified with biocompatible copolymers. Int $\mathrm{J}$ Nanomedicine. 2012;7:511-26.

70. Chen Q, Espey MG, Sun AY, Pooput C, Kirk KL, Krishna MC, et al. Pharmacologic doses of ascorbate act as a prooxidant and decrease growth of aggressive tumor xenografts in mice. Proc Natl Acad Sci. 2008;105(32):11105-9.

71. Carr AC, Maggini S. Vitamin C and Immune Function. Nutrients. 2017;9(11):125.

\section{PICTORIAL ABSTRACT}

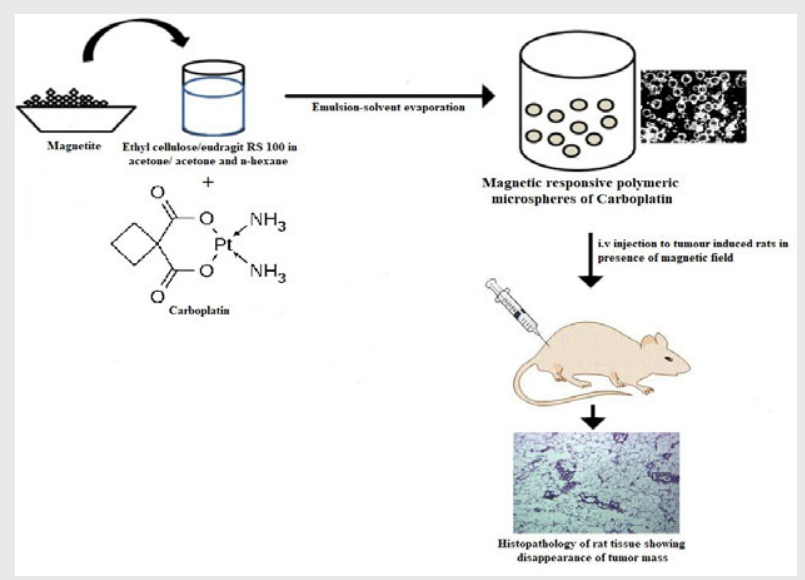

\section{SUMMARY}

Magnetic Nanospheres is a class of nanoparticle that are designed using magnetic field and have many advantages associated such as ability to bind targeted ligands, biodegradability and low toxicity. Hence, the super-magnetically modulated novel parenteral carrier of carboplatin capped with the vitamin $\mathrm{C}$ was formulated to increase the target ability of magnetic particle and synergize the impact of carboplatin with antioxidant effect. Current magnetic nanospheres provide a tremendous opportunity as targeted carriers for the treatment of breast cancer.

\section{About Authors}

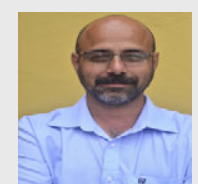

Dr. Ullas Prakash D'Souza, Assistant Professor, Department of Pharmacology, NGSM Institute of Pharmaceutical Sciences, NITTE (Deemed to be University), Mangaluru-575018.

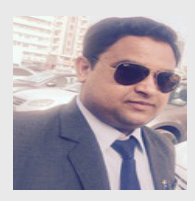

Mr. Nitish Kumar Rao, Department of Pharmaceutics, NGSM Institute of Pharmaceutical Sciences, NITTE (Deemed to be University), Mangaluru-575018.

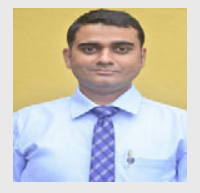

Dr. Akhilesh Dubey, Assistant Professor, Department of Pharmaceutics, NGSM Institute of Pharmaceutical Sciences, NITTE (Deemed to be University), Mangaluru-575018.

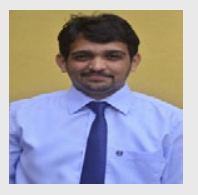

Mr. Ravi GS, Assistant Professor, Department of Pharmaceutics, NGSM Institute of Pharmaceutical Sciences, NITTE (Deemed to be University), Mangaluru-575018.

Cite this article: D'Souza UP, Rao N, Ravi GS, Dubey A. In vitro and in vivo Exploration of Super-magnetically Modulated Novel Parenteral Carrier: A Targeted Drug Delivery of Polymeric Carboplatin Nanosphere Capped with the Vitamin C to Treat Breast Cancer in Rats. Indian J of Pharmaceutical Education and Research. 2020;54(2s):s140-s153. 